\title{
Article \\ A Novel Phosphorescent Iridium(III) Complex Bearing Formamide for Quantitative Fluorine Anion Detection
}

\author{
Song Guo ${ }^{1,2} \mathbb{D}$, Chaoxiong Guo ${ }^{2}$, Zhao Lu ${ }^{2}$, Linlin $\mathrm{Du}^{2}$, Man Gao ${ }^{2}$, Shujuan Liu ${ }^{1}$, Yuanli Liu ${ }^{2, * \mathbb{D}}$ \\ and Qiang Zhao ${ }^{1, *}$
}

1 State Key Laboratory of Organic Electronics and Information Displays, Jiangsu Key Laboratory for Biosensors, Institute of Advanced Materials, Nanjing University of Posts and Telecommunications, Nanjing 210023, China; iamsguo@njupt.edu.cn (S.G.); iamsjliu@njupt.edu.cn (S.L.)

2 Guangxi Key Laboratory of Optical and Electronic Materials and Devices, College of Materials Science and Engineering, Guilin University of Technology (GLUT), Guilin 541004, China; 1020190104@glut.edu.cn (C.G.); 1020190105@glut.edu.cn (Z.L.); 2120190223@glut.edu.cn (L.D.); bx20202009@glut.edu.cn (M.G.)

* Correspondence: lyuanli@glut.edu.cn (Y.L.); iamqzhao@njupt.edu.cn (Q.Z.)

check for updates

Citation: Guo, S.; Guo, C.; Lu, Z.; Du, L.; Gao, M.; Liu, S.; Liu, Y.; Zhao, Q. A Novel Phosphorescent Iridium(III) Complex Bearing Formamide for Quantitative Fluorine Anion Detection. Crystals 2021, 11, 1190. https://doi.org/10.3390/ cryst11101190

Academic Editor: Thomas M. Klapötke

Received: 31 August 2021 Accepted: 27 September 2021 Published: 29 September 2021

Publisher's Note: MDPI stays neutral with regard to jurisdictional claims in published maps and institutional affiliations.

Copyright: (c) 2021 by the authors. Licensee MDPI, Basel, Switzerland. This article is an open access article distributed under the terms and conditions of the Creative Commons Attribution (CC BY) license (https:// creativecommons.org/licenses/by/ $4.0 /)$.

\begin{abstract}
Fluorine anion plays a critical role for human health, especially for the teeth and the skeletal system, and a deficiency or excess of fluorine anion will result in various diseases. Thus, the accurate and timely detection of fluorine content is of great importance. Herein, a novel and sensitive fluorine probe based on ionic iridium(III) complex using 5-formamide phenanthroline as an ancillary ligand was designed and synthesized rationally. The probe exhibited excellent performance for $\mathrm{F}^{-}$ detection in organic solvents. H-bonding between the fluoride and the amide proton was formed, thus changing the photophysical properties of the probe and leading to significant phosphorescence quenching. Nuclear magnetic resonance titration and theoretical calculations were carried out to understand the mechanism in detail. This is the first report of an iridium(III) complex probe for $\mathrm{F}^{-}$ detection based on the interaction between formamide and fluorine anion.
\end{abstract}

Keywords: fluorine anion; iridium(III) complex; formamide; phosphorescent emission

\section{Introduction}

Fluorine is an essential element for the human body. It is conducive to boosting the immune system and plays a vital physiological role in the health of bones, teeth, skin, and eyesight $[1,2]$. Fluorine mainly exists in the human body as a negative valence, such as fluoride anion $\left(\mathrm{F}^{-}\right)$[3]. The deficiency or excess intake of fluorine is closely related to various diseases, such as tooth decay, osteoporosis, dental fluorosis, and skeletal fluorosis. Further research has shown that high fluoride concentrations in food may cause serious neurotoxicity [4-6]. Thus, it is of great importance to quantitatively detect fluoride anion.

Many methods have been utilized for $\mathrm{F}^{-}$detection, including mass spectrometry, ${ }^{19} \mathrm{~F}$ nuclear magnetic resonance, atomic absorption spectroscopy, high performance liquid chromatography, sensor arrays, and so on [7-9]. Compared with the above methods, optical detection, especially luminescence detection, possesses unique advantages due to its high sensitivity, excellent selectivity, and low cost, making it suited to on-site analysis [10,11]. In addition, searching for a suitable probe is the key to $\mathrm{F}^{-}$detection. Phosphorescent transitional metal complexes, especially iridium (III) complex, have various unique advantages, such as tunable emission color, high quantum efficiency, rich excited states, and good photostability. Furthermore, the Ir(III) complex possesses a long emission lifetime from hundreds of nanoseconds to microseconds, which can eliminate the background fluorescent signal with short lifetime using a time-resolved photoluminescence technique, thereby enhancing the signal-to-noise ratio in detection [12-17]. $\mathrm{F}^{-}$, as a strong Lewis base, is the smallest anion with high charge density and strong affinity to silicon atoms. In 
view of this, our group has reported a series of $\mathrm{F}^{-}$probes base on $\operatorname{Ir}(\mathrm{III})$ complexes using the tert-butyldiphenylsilyl moiety as the specific reaction site for $\mathrm{F}^{-}[4,18,19]$. However, these probes are all single use and cannot be reused. As we know, $\mathrm{F}^{-}$probes based on active hydrogen can be reused after the addition of a trace proton. In 2016 we developed a low-level water probe based on $\operatorname{Ir}(\mathrm{III})$ complex including formamide moiety. However, the influence of $\mathrm{F}^{-}$on the photophysical properties of the probe was not studied in depth [20].

Herein, a novel and sensitive $\mathrm{F}^{-}$probe based on $\mathrm{Ir}(\mathrm{III})$ complex containing formamide unit was designed and synthesized rationally. To increase the stability of the complex, chlorinated 2-phenyllepidine substituted with trifluoromethyl instead of fluorine was selected as the main ligand, and 5-formamide phenanthroline was chosen as the ancillary ligand [21-23]. The probe showed outstanding performance for $\mathrm{F}^{-}$detection in organic solvents. Importantly, the change of configuration for the excited states before and after the addition of $\mathrm{F}^{-}$was investigated systematically. Simultaneously, the emission lifetime of the probe changed greatly after the addition of $\mathrm{F}^{-}$, which enabled the potential application for $\mathrm{F}^{-}$detection using a time-resolved photoluminescence technique, thereby improving the signal-to-noise ratio. Moreover, density functional theory (DFT) and time-dependent density functional theory (TDDFT) calculations were carried out to fully understand the relationship between the structure and photophysical properties. To the best of our knowledge, this is the first report of a quantitative probe for $\mathrm{F}^{-}$based on a formamide group.

\section{Materials and Methods}

Materials: 2-chloro-4-methylquinoline, 3-trifluoromethyl-4-chlorophenylboronic acid, palladium catalyst $\left(\mathrm{Pd}\left(\mathrm{PPh}_{3}\right)_{4}\right)$, 5-aminophenanthroline, potassium hexafluorophosphate, iridium trichloride trihydrate, and all of the solvents were purchased from Tansoole ${ }^{\circledR}$ and used without further purification.

Instrumentation: Nuclear magnetic resonance (NMR) spectra and mass spectra were obtained by a Bruker AMX-500 NMR instrument and Bruker autoflex matrix-assisted laser desorption/ionization time of flight mass spectrometer (MALDI-TOF MS). The UV-vis absorption spectrum was recorded on a UV3600 UV-Vis spectrophotometer (Shimadzu, Japan). The emission spectra and the emission lifetime were performed on a FluoroMax-4 fluorescence spectrophotometer (Horiba, Japan). The absolute quantum efficiency $(\Phi)$ of solutions was measured by an integrating sphere. The cyclic voltammetry measurements were accomplished in $\mathrm{CH}_{3} \mathrm{CN}\left(5.0 \times 10^{-4} \mathrm{M}\right)$ with a three-electrode system consisting of platinum working and counter electrodes and an $\mathrm{Ag} / \mathrm{AgNO}_{3}\left(0.01 \mathrm{M}\right.$ in $\left.\mathrm{CH}_{3} \mathrm{CN}\right)$ reference electrode at $\mathrm{N}_{2}$ atmosphere. Tetra-n-butylammonium hexafluorophosphate $(0.1 \mathrm{M}$ in $\mathrm{CH}_{3} \mathrm{CN}$ ) was selected as the electrolyte. The scan rate was $100 \mathrm{mV} / \mathrm{s}$ and reported with the reference to the ferrocene/ferrocenium $\left(\mathrm{Fc} / \mathrm{Fc}^{+}\right)$redox couple.

Calculation method: The ground-state geometrical configuration of 4 was optimized by density functional theory (DFT) with B3LYP functional. Based on the optimized ground state molecular structure, the time-dependent DFT (TDDFT) approach associated with the polarized continuum model (PCM) in dichloromethane media was carried out to obtain the vertical excitation energies of triplet states $(\mathrm{Tn})$. The calculation was performed using the Gaussian 16 B.01 suite of programs [24]. The SDD basis set was used to treat the iridium atom, whereas the $6-31 \mathrm{G}^{*}$ basis set was used to treat all other atoms. The contours of the highest occupied molecular orbital (HOMO) and lowest unoccupied molecular orbital (LUMO) were plotted by Multiwfn 3.8 program [25].

\subsection{Synthesis}

The synthetic routes of $\operatorname{Ir}(\mathrm{III})$ complex are shown in Figure 1. First, the main ligand was synthesized by Suzuki cross-coupling reaction using palladium catalyst. The auxiliary ligand was obtained by the formylation of 5-amido-1,10-phenanthroline using formic acid as the reaction reagent and solvent. $\mu$-dichloro bridged $\operatorname{Ir}(\mathrm{III})$ dimer complex and the end product Ir(III) complex were then fabricated by classic methods reported in the literature $[26,27]$. The structures of the compounds were confirmed through ${ }^{1} \mathrm{H}$ NMR $(500 \mathrm{MHz})$, 
${ }^{13} \mathrm{C}$ NMR (126 MHz), ${ }^{31} \mathrm{P}$ NMR (202 MHz) spectra and mass spectra. The photophysical properties of the complex were characterized via UV/vis absorption spectrometry, and steady-state and transient phosphorescence spectrometry.

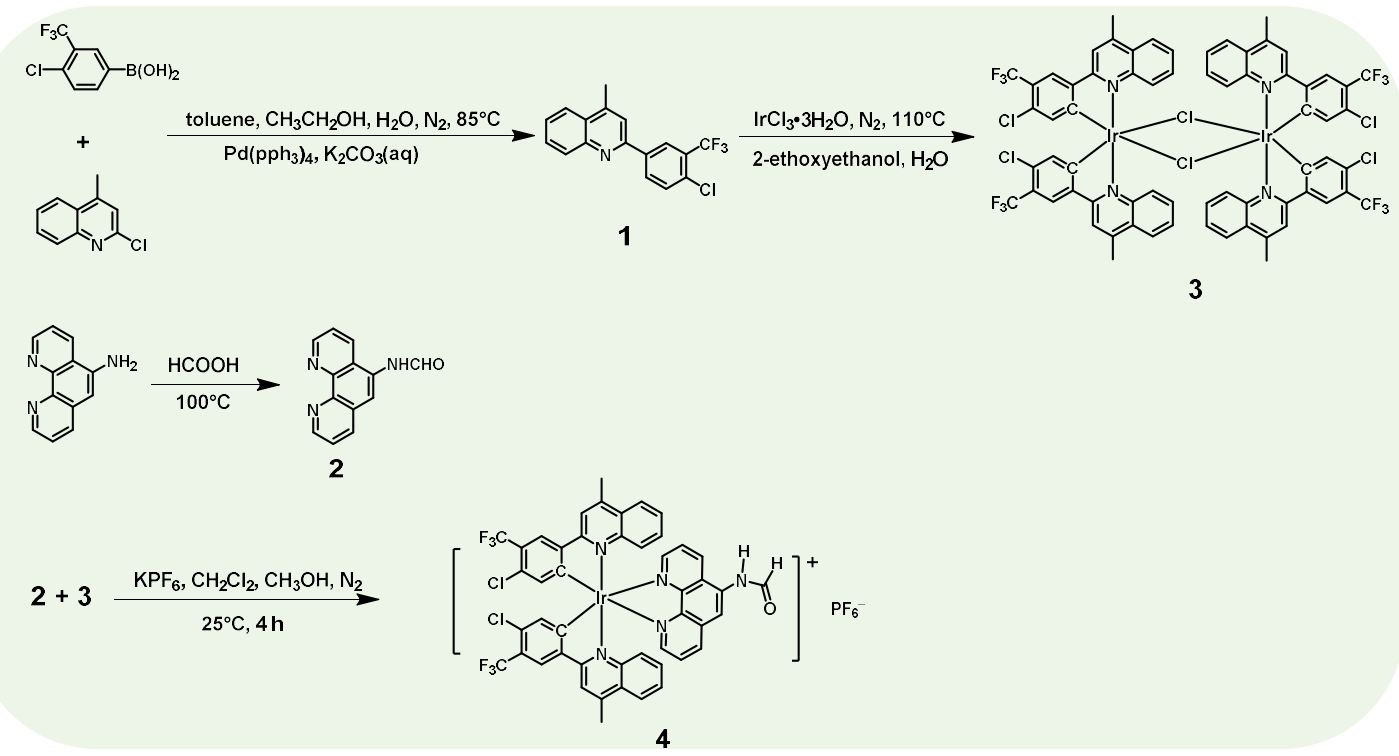

Figure 1. Synthetic routes of the iridium(III) complex.

\subsubsection{Synthesis of Main Ligand 1}

(4-Chloro-3-(trifluoromethyl)phenyl)boronic acid (1.89 g, $8.4 \mathrm{mmol})$, 2-chloro-4-methyl quinoline (1.5 g, $8.4 \mathrm{mmol}), 0.5 \mathrm{~g} \mathrm{~K}_{2} \mathrm{CO}_{3}$ and tetrakis(triphenylphosphine)palladium $(0.29 \mathrm{~g}$, $0.3 \mathrm{mmol}$ ) were added into a $150 \mathrm{~mL}$ flask. The mixture system was evacuated under vacuum and flushed with dry nitrogen three times. Degassed toluene $(45 \mathrm{~mL})$ was then injected. The system was heated to $85^{\circ} \mathrm{C}$ and stirred for $18 \mathrm{~h}$, and then cooled to room temperature. Next, $50 \mathrm{~mL}$ dichloromethane was added into the flask, the system was filtered, and the filtrate was collected; the solvent was then removed by rotary evaporator. The crude product was purified by flash chromatography (silica gel, ethyl acetate/petroleum ether, $75 / 1$ to $60 / 1, v / v)$, yielding a yellow solid. ${ }^{1} \mathrm{H}$ NMR (500 $\left.\mathrm{MHz}, \mathrm{CDCl}_{3}, \delta: \mathrm{ppm}\right): 8.52$ $(\mathrm{d}, J=2.05 \mathrm{~Hz}, 1 \mathrm{H}), 8.28(\mathrm{dd}, J=8.35 \mathrm{~Hz}, 2.05 \mathrm{~Hz}, 1 \mathrm{H}), 8.17(\mathrm{~d}, J=8.4 \mathrm{~Hz}, 1 \mathrm{H}), 8.02(\mathrm{dd}$, $J=8.30 \mathrm{~Hz}, 0.80 \mathrm{~Hz}, 1 \mathrm{H}), 7.75(\mathrm{ddd}, J=1.35 \mathrm{~Hz}, 6.90 \mathrm{~Hz}, 8.35 \mathrm{~Hz}, 1 \mathrm{H}), 7.69(\mathrm{~s}, 1 \mathrm{H}), 7.64(\mathrm{~d}$, $J=8.35 \mathrm{~Hz}, 1 \mathrm{H}), 7.59(\mathrm{ddd}, J=1.2 \mathrm{~Hz}, 6.85 \mathrm{~Hz}, 8.2 \mathrm{~Hz}, 1 \mathrm{H}), 2.79(\mathrm{~d}, J=0.8 \mathrm{~Hz}, 3 \mathrm{H})$.

\subsubsection{Synthesis of Auxiliary Ligand 2}

We added 5-amine-1,10-phenanthrolin $(1.0 \mathrm{~g}, 5.1 \mathrm{mmol})$ into the solvent formic acid $(50 \mathrm{~mL})$, and the mixture was then heated to $100^{\circ} \mathrm{C}$ for $7 \mathrm{~h}$. After cooling the system, the residual formic acid was removed by rotary evaporator, and a red-orange solid was then

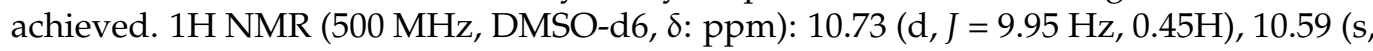
$1 \mathrm{H}), 9.14-9.13(\mathrm{~m}, 1.45 \mathrm{H}), 9.03-9.01(\mathrm{~m}, 1.45 \mathrm{~Hz}), 8.76-8.65(\mathrm{~m}, 2 \mathrm{H}), 8.59(\mathrm{~s}, 1 \mathrm{H}), 8.46-8.40$ $(\mathrm{m}, 2.50 \mathrm{H}), 7.92(\mathrm{~s}, 0.46 \mathrm{H}), 7.87-7.83(\mathrm{~m}, 1.45 \mathrm{H}), 7.77-7.72(\mathrm{~m}, 1.50 \mathrm{H})$.

\subsubsection{Synthesis of $\mu$-Dichloro Bridged Ir(III) Dimer Complex 3}

The $\mu$-dichloro bridged $\operatorname{Ir}(\mathrm{III})$ dimer complex 3 was synthesized according to the published literature [27]. $\mathrm{IrCl}_{3} \cdot 3 \mathrm{H}_{2} \mathrm{O}(1.23 \mathrm{~g}, 3.5 \mathrm{mmol})$ and ligand $\mathbf{1}(2.25 \mathrm{~g}, 7.0 \mathrm{mmol})$ were added into a mixture of 2-ethoxyethanol and deionized water $(60 \mathrm{~mL}, 3: 1 \mathrm{v} / \mathrm{v})$. The system was then heated to $110^{\circ} \mathrm{C}$ under $\mathrm{N}_{2}$ atmosphere for $15 \mathrm{~h}$. After the system was cooled, the orange solid was obtained by filtering the solution and then washed with deionized water and methanol. The solid was then dried using a vacuum drying oven. 


\subsubsection{Synthesis of $\operatorname{Ir}(\mathrm{III})$ Complex 4}

$\mu$-dichloro bridged Ir(III) dimer complex $3(1.0 \mathrm{~g}, 0.58 \mathrm{mmol})$, and auxiliary ligand 2 $(0.28 \mathrm{~g}, 1.27 \mathrm{mmol})$ were added into a mixture of degassed dichloromethane and methanol $(60 \mathrm{~mL}, 1: 1 \mathrm{v} / \mathrm{v})$, which was then stirred at room temperature for $5 \mathrm{~h}$ under nitrogen atmosphere. The solvent was then removed by rotary evaporator. The crude product was purified by column chromatography using dichloromethane/methanol as eluent. ${ }^{1} \mathrm{H}$ NMR (500 MHz, $\left.\mathrm{CD}_{2} \mathrm{Cl}_{2}, \delta: \mathrm{ppm}\right): 9.44(\mathrm{~s}, 1 \mathrm{H}), 8.96(\mathrm{~d}, J=7.7 \mathrm{~Hz}, 1 \mathrm{H}), 8.68(\mathrm{~s}, 1 \mathrm{H}), 8.59(\mathrm{~s}, 1 \mathrm{H})$, $8.55(\mathrm{~d}, J=4.7 \mathrm{~Hz}, 1 \mathrm{H}), 8.40-8.36(\mathrm{~m}, 4 \mathrm{H}), 8.09(\mathrm{~d}, J=4.3 \mathrm{~Hz}, 2 \mathrm{H}), 7.94(\mathrm{t}, J=7.2 \mathrm{~Hz}, 1 \mathrm{H}), 7.82$ $(\mathrm{dd}, J=8.2 \mathrm{~Hz}, 3.3 \mathrm{~Hz}, 2 \mathrm{H}), 7.77-7.71(\mathrm{~m}, 1 \mathrm{H}), 7.31(\mathrm{q}, J=7.5 \mathrm{~Hz}, 2 \mathrm{H}), 7.12(\mathrm{t}, J=9.35 \mathrm{~Hz}$, 2H), 6.91-6.81 (m, 2H), $6.78(\mathrm{~d}, J=6.9 \mathrm{~Hz}, 2 \mathrm{H}), 2.89(\mathrm{~s}, 3 \mathrm{H}), 2.88(\mathrm{~s}, 3 \mathrm{H})$. MALDI-TOF-MS $\mathrm{m} / z: 1056.47$ (Figures S2 and S3).

\section{Results}

\subsection{Structural Characterization}

As for compound 2, formamide has two isomeric forms, cis and trans. These two isomers can be distinguished by coupling constant in ${ }^{1} \mathrm{H}$ NMR; the coupling constants between - $\mathrm{NH}$ and $-\mathrm{CHO}$ for the cis and trans forms are $0-2.2 \mathrm{~Hz}$ and $8.0-10.0 \mathrm{~Hz}$, respectively [28,29]. The ${ }^{1} \mathrm{H}$ NMR spectrum of 2 is shown in Figure S1, the peak at $10.73 \mathrm{ppm}$ in low field was doublet splitting with the coupling constant of $9.95 \mathrm{~Hz}$, which can be ascribed to -NH in trans isomer; meanwhile, the singlet peak at $10.59 \mathrm{ppm}$ can be ascribed to -NH in cis isomer. The integral proportion for the two peaks reflected the molar ratio of the two isomers, which is about 0.45:1.0. However, the ${ }^{1} \mathrm{H}$ NMR spectrum (Figure S2) of compound 4 suggested that there were no isomers in the Ir(III) complex, and the singlet peak at $9.44 \mathrm{ppm}$ in low field can be assigned to - $\mathrm{NH}$ in the cis form. The attribution of $-\mathrm{NH}$ will be beneficial to analyzing the interaction between $\mathrm{F}^{-}$and $\operatorname{Ir}(\mathrm{III})$ complex.

\subsection{Photophysical Properties}

The photophysical properties of 4 were studied by UV-Vis absorption spectrometry and steady-state luminescence spectrometry, as shown in Figure 2a. The ultraviolet-visible (UV-Vis) absorption spectrum $\left(1.0 \times 10^{-5} \mathrm{M}\right.$, green line) showed an intense peak at $278 \mathrm{~nm}$, which can be ascribed to the ligand-centered (LC) transition, the absorption band at $325-350 \mathrm{~nm}$ was attributed to $\pi-\pi^{*}$ transitions of the cyclometalating ligands. In addition, the weak absorption peak between 375 to $450 \mathrm{~nm}$ can be assigned to spin-allowed singlet metal-to-ligand charge transfer $\left({ }^{1} \mathrm{MLCT}\right)$ and ligand-to-ligand charge transfer $\left({ }^{1} \mathrm{LLCT}\right)$ transitions [30]. The emission spectrum (Figure 2a, red line) of 4 in solid state exhibited a maximum peak at $577 \mathrm{~nm}$ and a shoulder peak at $550 \mathrm{~nm}$, and a large full width at half maximum of $136 \mathrm{~nm}$, because of the difference of aggregate state compared with the solution state. The lifetime (Figure S4) and absolute quantum efficiency were $123 \mathrm{~ns}$ and $13.76 \%$, respectively.

Complex 4 in dichloromethane solution exhibited a bright yellow emission visible by naked eye when excited at $365 \mathrm{~nm}$, as shown in Figure $2 \mathrm{~b}$ (inset). The emission spectra of 4 in dichloromethane solution at different concentrations under ambient conditions were investigated, as shown in Figure 2b, and they all possessed a maximum phosphorescent peak at $535 \mathrm{~nm}$ and a shoulder peak at $569 \mathrm{~nm}$, respectively. The similar profile of the spectra indicated that there existed extremely weak or no intermolecular interaction between the molecules in dilute solution. The emission lifetime and absolute luminescent efficiency in degassed dichloromethane solution at room temperature are $2.1 \mu$ s (Figure S5) and 15.36\%, indicative of the phosphorescent nature of emission. The phosphorescent behaviors of 4 in various solutions (1,4-dioxane, 2-ethoxyethanol, methanol, acetonitrile, tetrahydrofuran, $\mathrm{N}, \mathrm{N}$-dimethyl formamide, dimethylsulfoxide, and ethyl acetate) were then studied, as shown in Figure 2c; the similar peaks at 535 and $569 \mathrm{~nm}$ indicated that solvents with different polarities had no obvious influence on the emission spectra, and phosphorescent emission may have originated from the LC excited state. Next, the phosphorescence spectrum at $77 \mathrm{~K}$ for 4 was measured in 2-methyltetrahydrofuran (2-MeTHF), and compared 
with the emission spectra at room temperature, the low temperature spectrum exhibited slight blue-shift, peaking at 530,567 and $617 \mathrm{~nm}$, respectively, along with fine structures of vibronic bands (Figure $2 \mathrm{~d}$ ). The triplet energy of the triplet state $\left(\mathrm{T}_{1}\right)$ of 4 was calculated from the emission spectra at $77 \mathrm{~K}$ according to the highest energy-vibronic band, and it possessed a modest $\mathrm{T}_{1}$ energy at $2.35 \mathrm{eV}$. The photophysical data are summarized in Table 1.
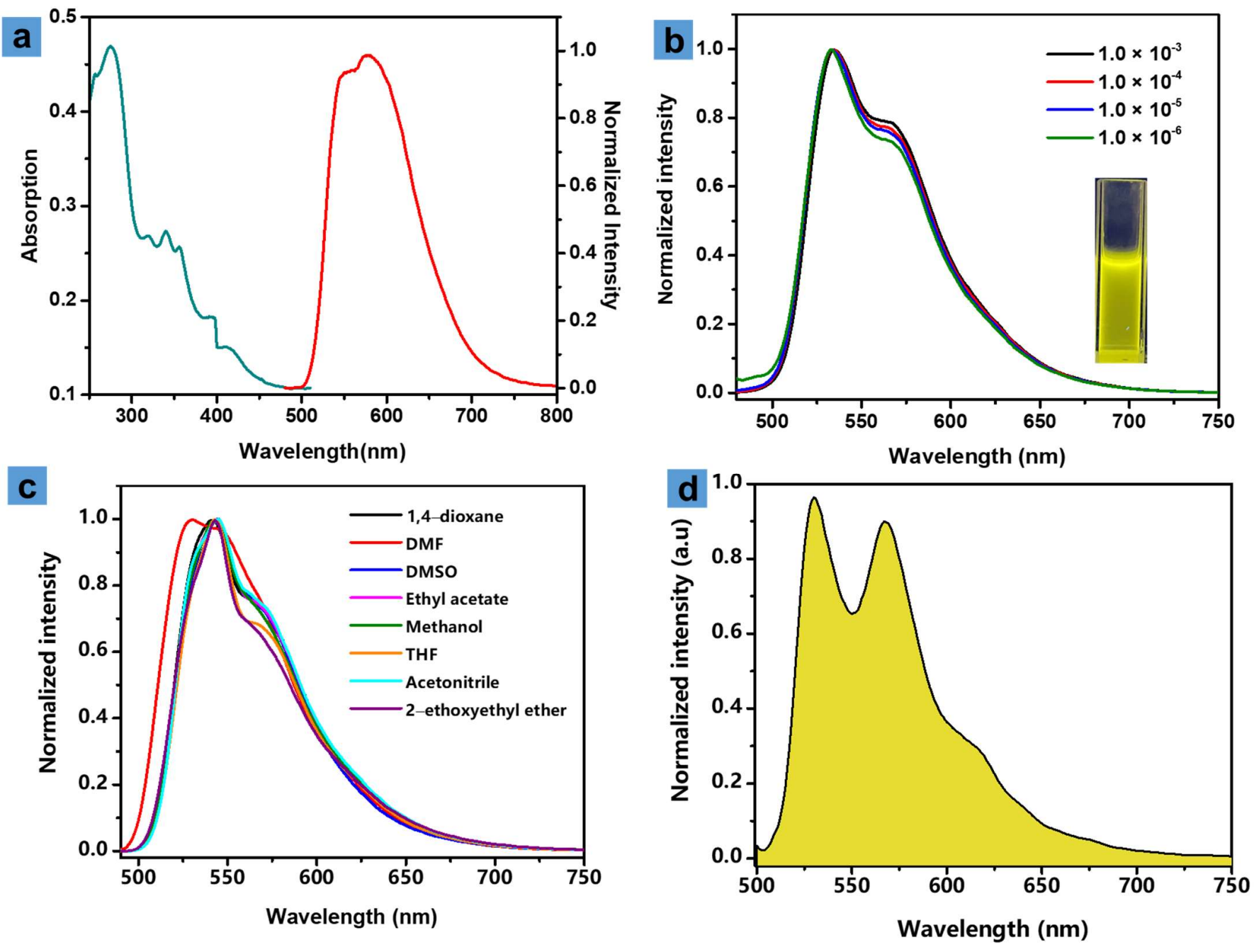

Figure 2. (a) Absorption spectrum of 4 in dichloromethane (green line) and the emission spectrum of 4 in solid state (red line); (b) emission spectra of 4 at different concentrations in dichloromethane at room temperature, inset: the photograph of 4 in dichloromethane excited at $365 \mathrm{~nm}\left(1.0 \times 10^{-3} \mathrm{M}\right)$; (c) emission spectra of 4 in different solvents at the concentration of $1.0 \times 10^{-5} \mathrm{M},(\mathbf{d})$ the low temperature emission spectrum of 4 at $77 \mathrm{~K}$ in $2-\mathrm{MeTHF}$.

Table 1. Photophysical data of complex 4.

\begin{tabular}{|c|c|c|c|c|c|c|c|c|}
\hline \multirow[b]{2}{*}{ Complex 4} & \multicolumn{2}{|l|}{ Absorption } & \multicolumn{6}{|l|}{ Emission } \\
\hline & $\lambda_{\mathrm{abs}}(\mathrm{nm})$ & $\begin{array}{c}\lambda_{\text {em }}(\mathrm{nm}) \\
(77 \mathrm{k})\end{array}$ & $\begin{array}{c}\lambda_{\mathrm{em}}(\mathrm{nm}) \\
\quad(\mathrm{RT})\end{array}$ & $\tau(\mu \mathrm{s})$ & $\Phi_{\mathrm{PL}}$ & $\begin{array}{c}\mathrm{E}_{\text {onset }}{ }^{\text {ox }} \\
(\mathrm{eV})\end{array}$ & $\begin{array}{l}E_{g}{ }^{a} \\
(e V)\end{array}$ & $\begin{array}{l}T_{1} b \\
(e V)\end{array}$ \\
\hline & $\begin{array}{c}278,325-350 \\
375-450\end{array}$ & $530 / 567$ & $535 / 566$ & 2.09 & 0.15 & 1.75 & 2.32 & 2.34 \\
\hline
\end{tabular}

The electrochemical behaviors of complex 4 in the $\mathrm{N}_{2}$-saturated acetonitrile solution at concentrations of $1.0 \times 10^{-5} \mathrm{M}$ were studied using cyclic voltammetry (Figure S6). The cyclic voltammetry curve exhibited an irreversible oxidation wave at the potential of $1.75 \mathrm{~V}$, which may be attributed to the oxidation of the iridium center [13]. 
Next, chemical stability and photostability of complex 4 were carried out by adding different anions, including $\mathrm{Cl}^{-}, \mathrm{Br}^{-}, \mathrm{NO}_{3}{ }^{-}, \mathrm{CH}_{3} \mathrm{COO}^{-}, \mathrm{HCO}_{3}{ }^{-}, \mathrm{CO}_{3}{ }^{2-}, \mathrm{SO}_{4}{ }^{2-}$, to the dichloromethane solution $\left(1.0 \times 10^{-5} \mathrm{M}\right)$ and illuminating at $365 \mathrm{~nm}\left(15 \mathrm{~mW} \mathrm{~cm}^{-2}\right)$, respectively, as shown in Figure 3a and Figure S9. The detailed experimental steps are presented in the Experimental Section in Supporting Information. With the exception of $\mathrm{CH}_{3} \mathrm{COO}^{-}$, the phosphorescent intensity at $535 \mathrm{~nm}$ exhibited little change, which indicated that 4 possessed excellent chemical stability and photostability. Subsequently, $\mathrm{F}^{-}$was added into the solution with different anions and the intensity dropped rapidly, suggesting the selectivity for $\mathrm{F}^{-}$in complex systems. However, the phosphorescent intensity of the samples containing $\mathrm{CH}_{3} \mathrm{COO}^{-}$dropped about 50 percent. Although the dissociation constant of $\mathrm{HCO}_{3}{ }^{-}\left(4.7 \times 10^{-11}\right)$ is far less than that of $\mathrm{HF}\left(3.53 \times 10^{-4}\right)$ and $\mathrm{CH}_{3} \mathrm{COOH}\left(1.8 \times 10^{-5}\right)$ in aqueous solution, the factors of solubility and basicity of the salts in $\mathrm{CH}_{2} \mathrm{Cl}_{2}$ solution should be considered simultaneously. In addition, the MS spectra of complex 4 containing $\mathrm{CO}_{3}{ }^{2-}$ and $\mathrm{CH}_{3} \mathrm{COO}^{-}$are presented in Figures S7 and S8, respectively. The molecular weight exhibited no change, peaking at $1056 \mathrm{~m} / \mathrm{z}$, the same as Figure S3, which suggested that the addition of $\mathrm{CO}_{3}{ }^{2-}, \mathrm{CH}_{3} \mathrm{COO}^{-}$showed almost no influence on the structure of the complex. Figure S9 was completed by recording the emission intensity at $535 \mathrm{~nm}$, and the very little change of intensity revealed that complex 4 exhibited good photostability.
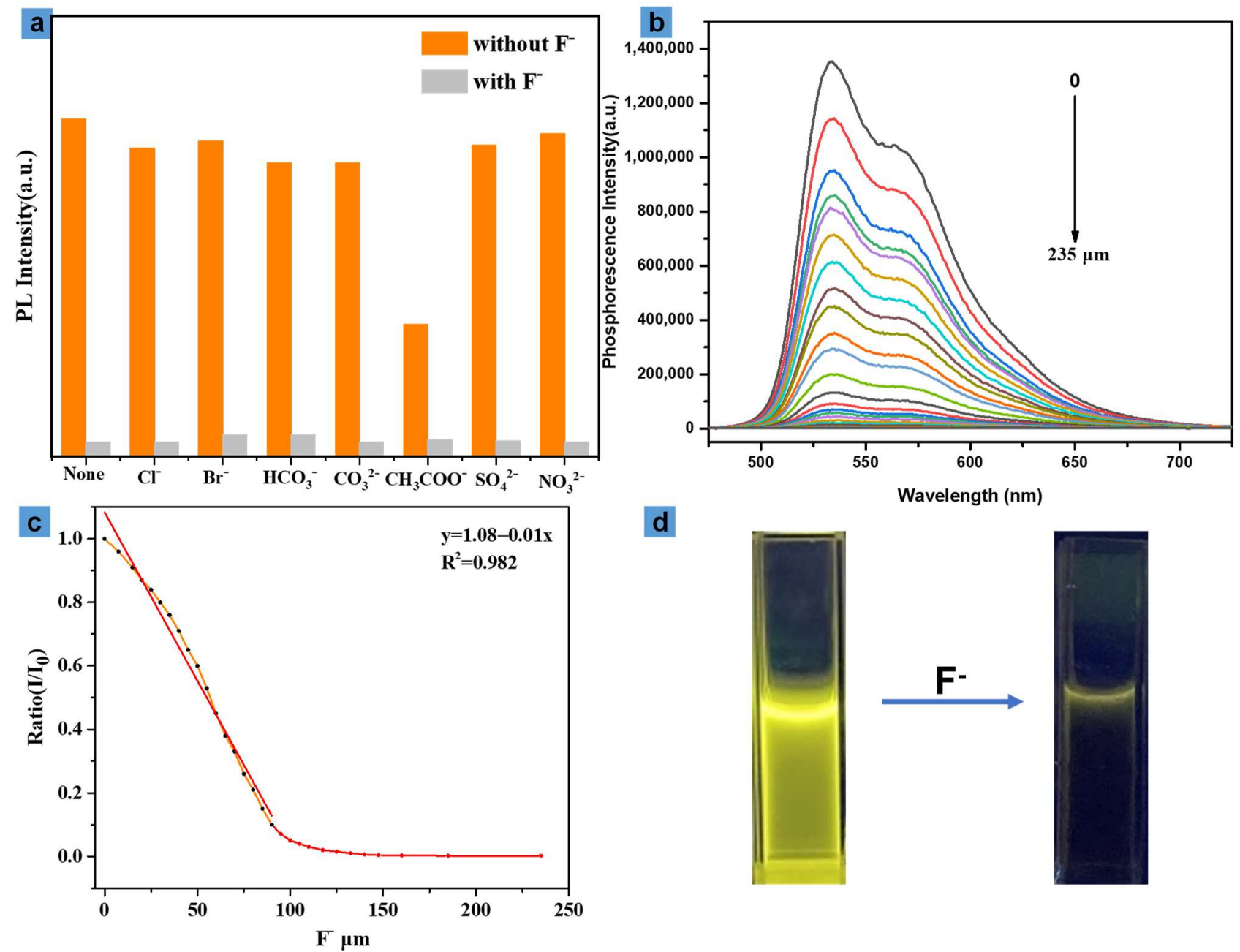

d

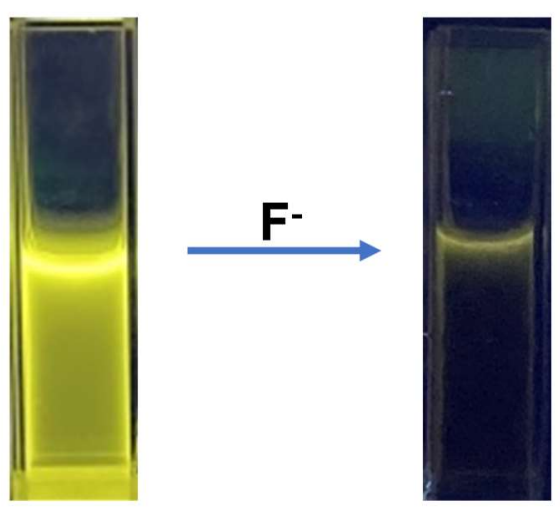

Figure 3. (a) the emission intensity of complex 4 in dichloromethane with other anions in the absence or presence of $\mathrm{F}^{-}$at $30{ }^{\circ} \mathrm{C}$; (b) The emission spectra for the response of complex 4 to fluoride anion in dichloromethane; (c) the plot of phosphorescent intensity ratio $\left(\mathrm{I} / \mathrm{I}_{0}\right)$ to the concentrations of fluoride anion, monitored at $535 \mathrm{~nm}$; (d) the photographs of the solution before and after the addition of fluoride anion. 


\subsection{Fluoride Anion Detection}

The phosphorescent response behaviors of complex 4 to $\mathrm{F}^{-}$in dichloromethane solution under ambient conditions were investigated in detail by titrations, as shown in Figure $3 b, c$ and Figure S10. The detailed experimental steps are presented in the Experimental Section in Supporting Information. The results suggested that the intensity of the phosphorescence at $535 \mathrm{~nm}$ declined gradually with the addition of fluoride anion; meanwhile, the emission lifetime also decreased gradually. The quenching efficiency $\eta$ $\left(\eta=\left(I_{0}-I\right) / I_{0}, I_{0}\right.$, and I were the phosphorescent intensity before and after the titration of $\mathrm{F}^{-}$, respectively) can represent the responsiveness of the complex for $\mathrm{F}^{-}$. When $\mathrm{F}^{-}$reached $100 \mu \mathrm{M}$, the intensity dropped by nearly 98 percent compared with that of the absence of $\mathrm{F}$, as shown in Figure 3d. There is a proximate linear relationship between the concentration of $\mathrm{F}^{-}$and phosphorescent intensity ratio $\left(\mathrm{I} / \mathrm{I}_{0}\right)$. The detection limit $(\mathrm{LOD}=3 \sigma / \mathrm{k})$ was calculated to be $\left(3.9 \times 10^{-2} \mu \mathrm{M}\right)$, which revealed that complex 4 was a potential candidate for the detection of low content of fluorine anion organic phases.

\subsection{Mechanism Analysis}

To understand the mechanism of the quenching behaviors in depth, NMR titration and theoretical calculations were carried out, as shown in Figure S11. As we know, fluoride has a strong binding capacity with reactive protons, and the addition of $\mathrm{F}^{-}$to the iridium can change the configuration of the excited states, thus leading to a quenching effect. The ${ }^{1} \mathrm{H}$ NMR spectra showed that the peak at $9.44 \mathrm{ppm}$ assigned to -NH shifted to low field and dwindled gradually along with the addition of $\mathrm{F}^{-}$, along with splitting into a doublet peak, the coupling constants are $8.05 \mathrm{~Hz}$ (mid spectrum) and $8.35 \mathrm{~Hz}$ (bottom spectrum). The different coupling constants may be due to the different distance between the hydrogen atom and fluorine atom. Thus, we speculate that when adding $\mathrm{F}^{-}$into the mixture system, $\mathrm{H}$-bonding between the fluoride and the amide proton was formed (Figure 4).

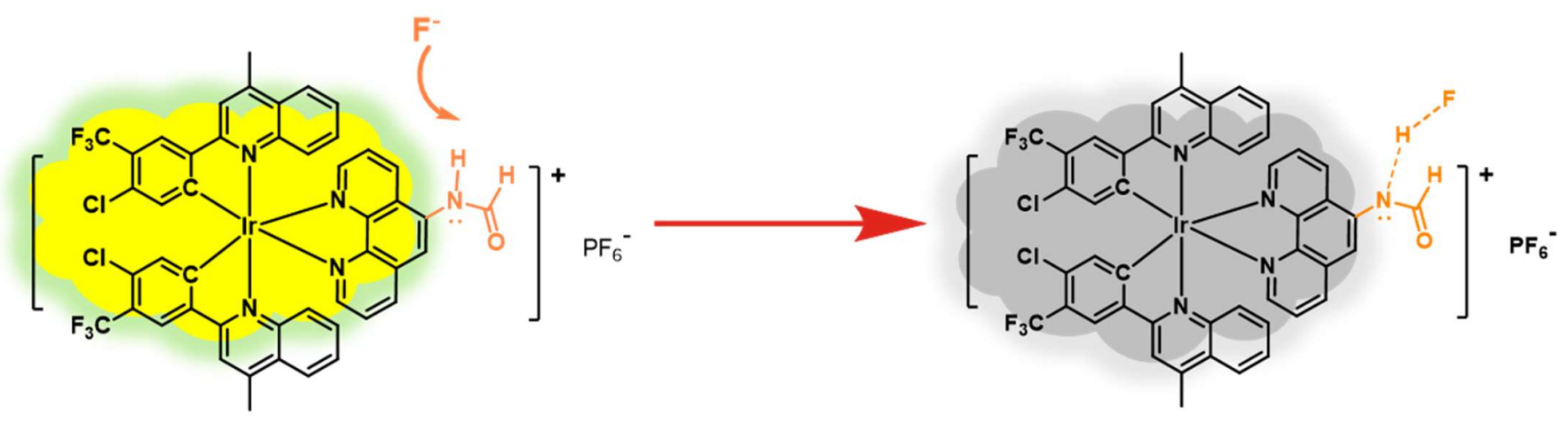

Figure 4. The working mechanism of the $\mathrm{F}^{-}$probe.

The geometrical configuration of 4 optimized via B3LYP is shown in Figure 5, and the results suggested that 4 adopted a slightly twisting hexa-coordinate octahedron structure, leading to no or weak intermolecular interactions, which was consistent with the similar profile of emission spectra at different concentrations. The frontier molecular orbital (FMO) was calculated by TDDFT, as shown in Table 2. The results revealed that the HOMO primarily distributed on the iridium center and $\pi$ orbital of quinolone unit of the main ligand, simultaneously, the LUMO was primarily distributed on the phenanthroline. Particularly, LUMO + 2 and HOMO-1 were principally located on the main ligand, without the auxiliary ligand. HOMO-1-LUMO + 2 and HOMO-LUMO transitions took up a large proportion, and the excited states of 4 were attributed to the mixture of MLCT transitions and LLCT transitions. We then simulated the molecular configuration of complex 4 with fluoride, as shown in Figure S12; because of the strong affinity of the fluorine and hydrogen, the distance between fluorine and hydrogen is $0.9735 \AA$, far shorter than that between nitrogen and hydrogen $(1.6722 \AA)$. Thus, the unit of F-H has little effect on the physical 
properties of the complex. Next, the calculation of FMO for complex $4+\mathrm{F}^{-}$was carried out based on the removal of hydrogen by fluorine. The results showed that, provided $-\mathrm{NH}$ was snatched by the fluoride anion, FMO would present a significant change. HOMO, $\mathrm{LUMO}+2$ and LUMO + 3 were primarily distributed on the auxiliary ligand, and LUMO was mainly located on the iridium center and main ligand. The proportion of the HOMOLUMO transition is much lower than that of HOMO-LUMO + 2 and HOMO-LUMO + 3 transitions, and the excited states were assigned to the LLCT transition, leading to a red-shift of the spectrum and efficiency drop and even luminescence quenching, which demonstrated well the quenching effect when adding $\mathrm{F}^{-}$into complex 4.

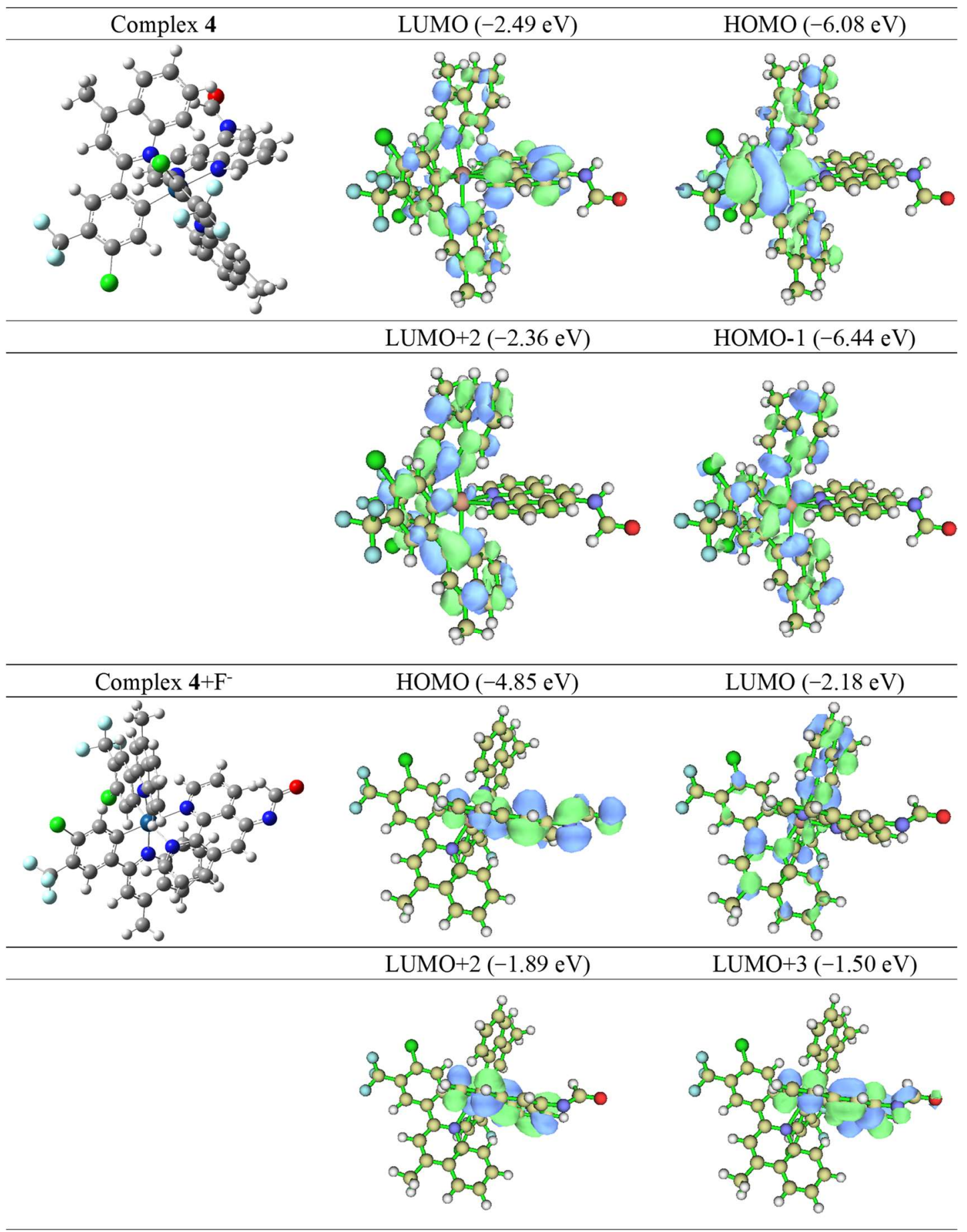

Figure 5. The distributions of molecular orbitals of 4 and $4+\mathrm{F}^{-}$. 
Table 2. The theoretical calculation of molecular orbitals of 4 and $4+\mathrm{F}^{-}$.

\begin{tabular}{ccccc}
\hline Complex & State & $\lambda / \mathbf{n m}$ & Configuration & Character \\
\hline & & $\mathrm{H}-1->\mathrm{L}+221.5 \%$, & MLCT/LLCT \\
4 & $\mathrm{~T}_{1}$ & 495.60 & $\mathrm{H}->\mathrm{L} 19.4 \%$, & MLCT/LLCT \\
$4+\mathrm{F}^{-}$ & $\mathrm{T}_{1}$ & 643.74 & $\mathrm{H}->\mathrm{L}+265.2 \%$, & $\mathrm{HLCT}$ \\
& & $\mathrm{H}->\mathrm{L}+320.0 \%$, & LLCT \\
& & & LLCT \\
\hline
\end{tabular}

\section{Conclusions}

In summary, a novel phosphorescent Ir(III) complex probe based on formamide for $\mathrm{F}^{-}$detection with low LOD was achieved successfully. The probe exhibited excellent recognition capability for quantitative analysis of fluorine anion in complex systems. Moreover, the working mechanism was calculated by TDDFT in detail, after the addition of $\mathrm{F}^{-}$, the excited states of the complex decay to LLCT transition, resulting in the quenching effect. In addition, the long emission lifetime of the complex allowed the probe to be a promising candidate with high signal to noise ratio via time-resolved technique. Next, we will focus on the development of a water-soluble near-infrared probe for $\mathrm{F}^{-}$detection and imaging in vivo.

Supplementary Materials: The following are available online at https://www.mdpi.com/article/ 10.3390/cryst11101190/s1, Figure S1: The ${ }^{1} \mathrm{H}$ spectrum of auxiliary ligand 2. Figure S2: The ${ }^{1} \mathrm{H}$ spectrum of complex 4. Figure S3: MALDI-TOF spectrum of complex 4. Figure S4: The decay curve of phosphorescent lifetime for complex 4 in solid state. Figure S5: The decay curve of phosphorescent lifetime for complex 4 in $\mathrm{CH}_{2} \mathrm{Cl}_{2}$. Figure $\mathrm{S6}$ : The cyclic voltammograms of 4 under a scan rate of $100 \mathrm{mV} / \mathrm{s}$ in $\mathrm{CH}_{3} \mathrm{CN}$. Figure S7: MALDI-TOF spectrum of complex 4 containing $\mathrm{CO}_{3}{ }^{2-}$. Figure S8: MALDI-TOF spectrum of complex 4 containing $\mathrm{HCO}_{3}{ }^{-}$. Figure S9: The photostability of complex 4 excited at $365 \mathrm{~nm}$. Figure S10: The emission spectra for the response of complex 4 to fluoride anion in dichloromethane. Figure S11: The ${ }^{1} \mathrm{H}$ NMR titration for complex 4. Figure S12: The molecular configuration of complex 4 with fluorinion. Figure S13: The ${ }^{1} \mathrm{H}$ spectrum of main ligand. Figure S14: The ${ }^{13} \mathrm{C}$ spectrum of complex 4 . Figure S15: The ${ }^{31} \mathrm{P}$ spectrum of complex 4 .

Author Contributions: Conceptualization, S.G.; methodology, L.D.; software, M.G.; formal analysis, S.L.; investigation, S.G.; resources, Y.L.; data curation, C.G. and Z.L.; writing—original draft preparation, S.G.; writing - review and editing, Q.Z. All authors have read and agreed to the published version of the manuscript.

Funding: This research was funded by the Natural Science Foundation of Jiangsu Province of China (BK20180760); the National Natural Science Foundation of China (21864010); Project of Guangxi Natural Science Foundation (2020GXNSFBA297098); and the Open Project Program of Guangxi Key Laboratory of Optical and Electronic Materials and Devices (20AA-10).

Data Availability Statement: The data presented in this study are available upon request from the the first author or the corresponding authors.

Acknowledgments: We thanks for the MALDI-TOF measurement provided by Liucheng Gui from Guangxi Normal University.

Conflicts of Interest: The authors declare no conflict of interest.

\section{References}

1. Baykov, A.A.; Fabrichniy, L.P.; Pohjanjoki, P.; Zyryanov, A.B.; Lahti, R. Fluoride effects along the reaction pathway of pyrophosphatase: evidence for a second enzyme-pyrophosphate intermediate. Biochemistry 2000, 39, 11939-11947. [CrossRef] [PubMed]

2. Rochman, C.M.; Munno, K.; Box, C.; Cummins, A.; Zhu, X.; Sutton, R. Think global, act local: Local knowledge is critical to inform positive change when it comes to microplastics. Environ. Sci. Technol. 2021, 55, 4-6. [CrossRef] [PubMed]

3. Máñez, R.M.; Sancenón, F. Fluorogenic and chromogenic chemosensors and reagents for anions. Chem. Rev. 2003, 103, $4419-4476$. [CrossRef] [PubMed]

4. Cametti, M.; Rissanen, K. Recognition and sensing of fluoride anion. Chem. Commun. 2009, 2809-2829. [CrossRef] 
5. Qiu, H.; Ye, M.C.; Zhang, M.D.; Zhang, X.L.; Zhao, Y.; Yu, J.H. Nano-hydroxyapatite encapsulated inside an anion exchanger for efficient defluoridation of neutral and weakly alkaline water. ACS ESET Eng. 2021, 1, 46-54.

6. Hättig, C.; Klopper, W.; Köhn, A.; Tew, D.P. Explicitly correlated electrons in molecules. Chem. Rev. 2012, 112, 4-74. [CrossRef]

7. Dhillon, A.; Nair, M.; Kumar, D. Analytical methods for determination and sensing of fluoride in biotic and abiotic sources: A review. Anal. Methods 2016, 8, 5338-5352. [CrossRef]

8. D'Ulivo, A.; Pagliano, E.; Onor, M.; Pitzalis, E.; Zamboni, R. Vapor Generation of Inorganic anionic species after aqueous phase alkylation with trialkyloxonium tetrafluoroborates. Anal. Chem. 2009, 81, 6399-6406. [CrossRef]

9. Cao, Z.B.; Cao, Y.; Kubota, R.; Sasaki, Y.; Asano, K.; Lyu, X.J.; Zhang, Z.J.; Zhou, Q.; Zhao, X.L.; Xu, X.; et al. Fluorescence anion chemosensor array based on pyrenylboronic acid. Front. Chem. 2020, 8, 414. [CrossRef]

10. Chen, Z.J.; Yan, P.; Zou, L.; Zhao, M.L.; Jiang, J.Y.; Liu, S.J.; Zhang, K.Y.; Huang, W.; Zhao, Q. Using ultrafast responsive phosphorescent nanoprobe to visualize elevated peroxynitrite in vitro and in vivo via ratiometric and time-resolved photoluminescence imaging. Adv. Healthc. Mater. 2018, 7, 1800309. [CrossRef]

11. Chen, Z.J.; Meng, X.C.; Xie, M.J.; Shi, Y.X.; Zou, L.; Guo, S.; Jiang, J.Y.; Liu, S.J.; Zhao, Q. A self-calibrating phosphorescent polymeric probe for measuring $\mathrm{PH}$ fluctuations in subcellular organelles and the zebrafish digestive tract. J. Mater. Chem. C 2020, 8, 2265-2271. [CrossRef]

12. Guo, S.; Han, M.P.; Chen, R.Z.; Zhuang, Y.L.; Zou, L.; Liu, S.J.; Huang, W.; Zhao, Q. Mitochondria-localized iridium(III) complexes with anthraquinone groups as effective photosensitizers for photodynamic therapy under hypoxia. Sci. China Chem. 2019, 62, 1639-1648. [CrossRef]

13. Tao, P.; Li, W.L.; Zhang, J.; Guo, S.; Zhao, Q.; Wang, H.; Wei, B.; Liu, S.J.; Zhou, X.H.; Yu, Q.; et al. Facile synthesis of highly efficient lepidine-based phosphorescent iridium(III) complexes for yellow and white organic light-emitting diodes. Adv. Funct. Mater. 2016, 26, 881-894. [CrossRef]

14. Feng, Z.Y.; Tao, P.; Zou, L.; Gao, P.L.; Liu, Y.; Liu, X.; Wang, H.; Liu, S.J.; Dong, Q.C.; Li, J.; et al. Hyperbranched phosphorescent conjugated polymer dots with iridium(III) complex as the core for hypoxia imaging and photodynamic therapy. ACS Appl. Mater. Interfaces 2017, 9, 28319-28330. [CrossRef]

15. Jiang, J.Y.; Zhang, C.Q.; Lin, W.P.; Liu, Y.H.; Liu, S.J.; Xu, Y.J.; Zhao, Q.; Huang, W. Long-lived phosphorescent iridium(III) complexes conjugated with cationic polyfluorenes for heparin sensing and cellular imaging. Macromol. Rapid Commun. 2015, 36, 640-646. [CrossRef] [PubMed]

16. Zhang, K.Y.; Gao, P.L.; Sun, G.L.; Zhang, T.W.; Li, X.L.; Liu, S.J.; Zhao, Q.; Lo, K.K.W.; Huang, W. Dual-phosphorescent iridium(iii) complexes extending oxygen sensing from hypoxia to hyperoxia. J. Am. Chem. Soc. 2018, 140, 7827-7834. [CrossRef] [PubMed]

17. Zhang, K.Y.; Zhang, T.W.; Wei, H.J.; Wu, Q.; Liu, S.J.; Zhao, Q.; Huang, W. Phosphorescent iridium(iii) complexes capable of imaging and distinguishing between exogenous and endogenous analytes in living cells. Chem. Sci. 2018, 9, 7236-7240. [CrossRef] [PubMed]

18. Zhao, Q.; Zhang, C.Q.; Liu, S.J.; Liu, Y.H.; Zhang, K.Y.; Zhou, X.B.; Jiang, J.Y.; Xu, W.J.; Yang, T.S.; Huang, W. Dual-emissive polymer dots for rapid detection of fluoride in pure water and biological systems with improved reliability and accuracy. Sci. Rep. 2015, 5, 16420. [CrossRef]

19. Chen, Z.J.; Jiang, J.Y.; Zhao, W.L.; Hu, X.M.; Xie, M.J.; Li, F.Y.; Liu, S.J.; Zhao, Q. An aggregation-induced phosphorescent emission-active iridium(iii) complex for fluoride anion imaging in living cells. J. Organomet. Chem. 2021, 932, 121644. [CrossRef]

20. Guo, S.; Ma, Y.; Liu, S.J.; Yu, Q.; Xu, A.Q.; Han, J.M.; Wei, L.W.; Zhao, Q.; Huang, W. A phosphorescent ir(iii) complex with formamide for the luminescence determination of low-level water content in organic solvents. J. Mater. Chem. C 2016, 4, 6110-6116. [CrossRef]

21. Tao, P.; Zheng, X.K.; Wei, X.Z.; Lau, M.T.; Lee, Y.K.; Li, Z.K.; Guo, Z.L.; Zhao, F.Q.; Liu, X.; Liu, S.J.; et al. Chlorinated yellow phosphorescent cyclometalated neutral iridophosphors featuring broad emission bandwidths for white electroluminescence. Mater. Today Energy 2021, 21, 100773. [CrossRef]

22. Zheng, X.K.; Zhao, F.Q.; Yin, M.N.; Qian, C.; Bi, S.H.; Tao, P.; Miao, Y.Q.; Liu, S.J.; Zhao, Q. New trifluoromethyl modified iridium(iii) complex for high-efficiency sky-blue phosphorescent organic light-emitting diode. Tetrahedron Lett. 2021, 75, 153181. [CrossRef]

23. Tao, P.; Zheng, X.K.; Lee, Y.K.; Wang, G.L.; Li, F.Y.; Li, Z.K.; Zhao, Q.; Miao, Y.Q.; Wong, W.Y. Vacuum-sublimable ionic yellow phosphorescent iridium(iii) complexes with broad emission for white electroluminescence. Adv. Photonics Res. 2021, 2, 2100115. [CrossRef]

24. Frisch, M.J.; Trucks, G.W.; Schlegel, H.B.; Scuseria, G.E.; Robb, M.A.; Cheeseman, J.R.; Scalmani, G.; Barone, V.; Petersson, G.A.; Nakatsuji, H.; et al. Gaussian 09, Revision A.02; Gaussian, Inc.: Wallingford, CT, USA, 2016.

25. Lu, T.; Chen, F.W. Multiwfn: A multifunctional wavefunction analyzer. J. Comput. Chem. 2012, 33, 580-592. [CrossRef]

26. Matsuo, N. Benzo[h]quinolin-10-yl-n iridium(iii) complexes. Bull. Chem. Soc. Jpn. 1974, 47, 767-768.

27. Sun, H.B.; Liu, S.J.; Lin, W.P.; Zhang, K.Y.; Lv, W.; Huang, X.; Huo, F.W.; Yang, H.R.; Jenkins, G.; Zhao, Q.; et al. Smart responsive phosphorescent materials for data recording and security protection. Nat. Commun. 2014, 5, 3601. [CrossRef]

28. Han, J.M.; Guo, S.; Wang, J.; Wei, L.W.; Zhuang, Y.L.; Liu, S.J.; Zhao, Q.; Zhang, X.W.; Huang, W. Circularly polarized phosphorescent electroluminescence from chiral cationic iridium(iii) isocyanide complexes. Adv. Opt. Mater. 2017, 5, 1700359. [CrossRef] 
29. Wang, R.B.; Cai, K.M.; Wang, H.; Yin, C.; Cheng, J.J. A caged metabolic precursor for dt-diaphorase-responsive cell labeling. Chem. Commun. 2018, 54, 4878-4881. [CrossRef]

30. Tao, P.; Miao, Y.Q.; Wang, H.; Xu, B.S.; Zhao, Q. High-performance organic electroluminescence: Design from organic lightemitting materials to devices. Chem. Rec. 2019, 19, 1531-1561. [CrossRef] 